\title{
Electroconvulsive seizures activate anorexigenic signals in the ventromedial nuclei of the hypothalamus.
}

\section{$\operatorname{AUTHOR}(\mathrm{S}):$}

Segi-Nishida, Eri; Sukeno, Mamiko; Imoto, Yuki; Kira, Toshihiko; Sakaida, Mari; Tsuchiya, Soken; Sugimoto, Yukihiko; Okuno, Yasushi

\section{CITATION:}

Segi-Nishida, Eri ... [et al]. Electroconvulsive seizures activate ano rexigenic signals in the ventromedial nuclei of the hypothalamus.. Neuropharmacology 2013, 71: 164-173

\section{ISSUE DATE:}

2013-08

URL:

http://hdl.handle.net/2433/175281

\section{RIGHT:}

(c) 2013 Elsevier Ltd.; この論文は出版社版でありません。引用の際には 出版社版をご確認ご利用ください。; This is not the published version. Please cite only the published version. 
Neuropharmacology-Regular Manuscript

Electroconvulsive seizures activate anorexigenic signals in the ventromedial nuclei of the hypothalamus

Abbreviated title: ECS-induced anorexigenic signals in VMH

Eri Segi-Nishida ${ }^{1, *}$, Mamiko Sukeno ${ }^{1}$, Yuki Imoto $^{2}$, Toshihiko Kira ${ }^{2}$, Mari Sakaida ${ }^{2}$, Soken Tsuchiya $^{3}$, Yukihiko Sugimoto ${ }^{3}$, Yasushi Okuno ${ }^{1}$

${ }^{1}$ Department of Systems Biosciences for Drug Discovery, and ${ }^{2}$ Department of Physiological Chemistry, Graduate School of Pharmaceutical Sciences, Kyoto University, Yoshida Shimoadachi-cho, Sakyo-ku, Kyoto 606-8501, Japan, ${ }^{3}$ Department of Pharmaceutical Biochemistry, Graduate School of Pharmaceutical Sciences, Kumamoto University, Oe-honmachi, Kumamoto 862-0973, Japan

*, Correspondence should be addressed to

Dr. Eri Segi-Nishida (eri.segi.nishida@pharm.kyoto-u.ac.jp)

Department of Systems Biosciences for Drug Discovery, Graduate School of Pharmaceutical Sciences, Kyoto University, Yoshida Shimoadachi-cho, Sakyo-ku, Kyoto 606-8501, Japan. TEL: +81-75-753-4537; FAX: +81-75-753-4559. 


\begin{abstract}
The ventromedial nucleus of the hypothalamus $(\mathrm{VMH})$ plays an important role in feeding and energy homeostasis. Electroconvulsive seizure (ECS) therapy is highly effective in the treatment of several psychiatric diseases, including depression, but may also have beneficial effects in other neurological diseases. Although it has been reported that the neurons of the VMH are strongly activated by ECS stimulation, the specific effects of ECS in this hypothalamic subnucleus remain unknown. To address this issue, we investigated the changes in gene expression in microdissected-VMH samples in response to ECS in mice, and examined the behavioral effects of ECS on feeding behavior. ECS significantly induced the expression of immediate-early genes such as Fos, Fosb, and Jun, as well as Bdnf, Adcyapl, Hrhl, and Crhr2 in the VMH. Given that signals of these gene products are suggested to have anorexigenic roles in the $\mathrm{VMH}$, we also examined the effect of ECS on food intake and body weight. Repeated ECS had a suppressive effect on food intake and body weight gain under both regular and high-fat diet conditions. Furthermore, gold-thioglucose-induced hypothalamic lesions, including the $\mathrm{VMH}$ and the arcuate nucleus, abolished the anorexigenic effects of ECS, indicating the requirement for the activation of the hypothalamus. Our data show an effect of ECS on increased expression of anorexigenic factors in the $\mathrm{VMH}$, and suggest a role in the regulation of energy homeostasis by ECS.
\end{abstract}

Keywords: electroconvulsive seizure, ventromedial nucleus hypothalamus, laser-capture microdissection, anorexigenic signals 
Segi-Nishida et al.

\section{Introduction}

The hypothalamus regulates food intake and body weight. Classical stereotactic lesioning studies led to a hypothesis by which the ventromedial nucleus of the hypothalamus (VMH) and the arcuate nucleus (ARC) mediates a satiety signal (King, 2006). While numerous recent experiments have shown that the ARC is a critical regulator of energy balance (Elmquist et al. 2005), several lines of inquiry, such as genetic disruption of the VMH induced by a mutation in the Nr5al (SF-1) gene, have also confirmed the importance of the VMH in maintaining energy homeostasis (Majdic et al. 2002).

Electroconvulsive seizure (ECS) therapy has long been known as an effective and rapid treatment for drug-resistant depression (Pagnin et al. 2004). ECS therapy is also effective in reducing psychiatric symptoms in patients with Alzheimer's and Parkinson's diseases (Sutor et al. 2008; Moellentine et al. 1998). Moreover, there have been several reports describing beneficial effects of ECS on motor symptoms in Parkinson's disease (Popeo et al. 2009), and on chronic pain in neuropathy cases (Abdi et al. 2004). These data suggest that ECS may have other unidentified effects, which could prove to be useful in the treatment of other neurological disorders. Since investigations into the molecular mechanisms of ECS have focused primarily on its antidepressant effects, the molecular and cellular changes induced in the prefrontal cortex and the hippocampus have been well studied in animal models. These studies show that ECS increases the expression of neurotrophic/growth factors, and the proliferation of neural progenitors, glial cells and endothelial cells in these regions (Segi-Nishida 2011), and the relevance of such changes to antidepressant effects has been discussed (Shirayama et al. 2002; Santarelli et al. 2003). However, it has also been reported that ECS affects other brain regions, including the hypothalamus (Jansson et al. 2006). Hypothalamic systems are responsible for the regulation of basal homeostatic functions, such as appetite, sleep, circadian rhythms, and sexual drive, and disturbed homeostatic mechanisms are common symptoms of depression. Among the hypothalamic 
nuclei, the neurons of the VMH are most strongly activated by ECS stimulation. However, whether ECS regulates the function of the $\mathrm{VMH}$, and if so, what are the specific effects of ECS in this subnucleus, remains unknown.

In this study, we first investigated changes in gene expression in microdissected-VMH samples occurring in response to ECS in mice. Then, to gain insight into the effects of ECS in the VMH, we examined the behavioral effects of ECS. Here, we found that ECS increases the expression of anorexigenic-related genes, such as $B d n f$, Adcyap1, Hrh1, and Crhr2 in the VMH, and that ECS decreases food intake and body weight gain through the activation of anorexigenic signals in the hypothalamus. 
Segi-Nishida et al.

\section{Materials and Methods}

2.1. Animals. Male C57BL/6N mice (9-12 weeks old) (Japan SLC, Hamamatsu, Japan) were housed under standard illumination parameters with a 12-h light/dark cycle and ad libitum access to water and food. Male C57BL/6JHamSlc-ob/ob mice were purchased from Japan SLC, housed under the same conditions, and used at 9 weeks of age. Animal use and procedures were in accordance with the National Institute of Health guidelines and approved by the Committee of Animal Research of Kyoto University Faculty of Pharmaceutical Sciences. All efforts were made to minimize the number of animals used in these experiments.

2.2. ECS treatment and tissue preparation. Bilateral ECS (25-mA current; 1 -s shock duration; 100-pulse/s frequency; 0.5-ms pulse width) was administered via moistened, spring-loaded ear-clip electrodes to very lightly isoflurane-anesthetized mice using a pulse generator (ECT Unit; Ugo Basile, Comeria, Italy). The shock administered produced a tonic seizure phase, characterized by the extension of all 4 limbs, that lasted for more than $10 \mathrm{~s}$. The sham-treated animals were handled in an identical manner to the ECS-treated animals, without the administration of shock. For immunohistochemical analysis, mice were given either a single ECS treatment, or 1 ECS treatment daily for 7 days. Mice were perfused with saline and $4 \%$ paraformaldehyde $2 \mathrm{~h}$ after a single or 7 sets of ECS treatment. The whole brain was dissected and postfixed overnight at $4^{\circ} \mathrm{C}$, followed by cryoprotection in $20 \%$ sucrose and freezing on dry ice until sectioning. The control-brain was collected $2 \mathrm{~h}$ after a single sham treatment. For microdissection and in situ hybridization, mice were again given a single ECS treatment, or 1 ECS treatment daily for 7 days. Mice were killed 2 h, 6 h, or $24 \mathrm{~h}$ after a single or 7 sets of ECS treatment. The whole brain was quickly removed, rapidly frozen on dry ice, and then stored at $-20^{\circ} \mathrm{C}$ until further processing. The control brain was collected $2 \mathrm{~h}$ after either the single or 7 sets of sham treatment. For BDNF immunoblot analysis, mice were 
given either $1 \mathrm{ECS}$ or sham treatment daily for 7 days. Mice were killed $6 \mathrm{~h}$ after the 7 sets of ECS or sham treatment were completed. The whole brain was quickly removed, and a coronal slice was made between bregma $-1.22 \mathrm{~mm}$ and $-2.06 \mathrm{~mm}$ (Franklin and Paxinos, 2008). The mediobasal hypothalamus, including the $\mathrm{VMH}$, was then excised under a microscope. All samples were immediately frozen on dry ice and stored at $-20^{\circ} \mathrm{C}$ until further processing.

2.3. Laser microdissection. Cryocut sections (thickness, $7 \mu \mathrm{m}$ ) were placed on uncoated glass slides (Jung CM3000 cryostat; Leica Microsystems, Wetzlar, Germany), fixed, stained, and dehydrated using the following protocol: $75 \%$ ethanol for $30 \mathrm{~s}$, RNase-free water for $30 \mathrm{~s}$, 20-s staining using Histogene (Applied Biosystems, Carlsbad, CA), RNase-free water for 30 s, $75 \%$ ethanol for $30 \mathrm{~s}, 95 \%$ ethanol for $30 \mathrm{~s}, 100 \%$ ethanol twice for $30 \mathrm{~s}$ each, and xylene for $5 \mathrm{~min}$. Subsequently, the sections were vacuum dried for $15 \mathrm{~min}$, and laser microdissection was performed using the Pixell Ile Laser Capture Microdissection system (Applied Biosystems). Determination of the VMH area was based on the Mouse Brain Atlas: anteroposterior from bregma level -1.46 to -1.70 (Franklin and Paxinos, 2008). Immediately after microdissection, samples were dissolved in denaturing buffer from the RNeasy Micro kit (Qiagen, St. Louis, MO), and stored at $-80^{\circ} \mathrm{C}$ until RNA purification was performed.

2.3. RNA purification. Total RNA from laser-microdissected samples was isolated using an RNeasy Micro Kit (Qiagen). All steps were performed in accordance with the manufacturer's instructions. The quality and size distribution of the total RNA was confirmed by an RNA 6000 Pico Lab-Chip and the Agilent Bioanalyzer (Agilent, Palo Alto, CA).

2.4. Quantitative real-time PCR. Total RNA (1 ng) of the VMH from 3 to 4 individual animals was converted to cDNA using the SuperScript VILO cDNA Synthesis kit (Invitrogen, 
Carlsbad, CA). Quantitative real-time PCR (qPCR) was performed in a LightCycler (Roche, Mannheim, Germany) using FastStart DNA Master SYBR Green I (Roche). Relative gene concentrations were normalized against those of $18 \mathrm{~S}$ ribosomal RNA. The specificity of the primers was confirmed by gel electrophoresis and determination of the melting temperature (data not shown). RNA samples transcribed in the absence of reverse transcriptase were used as negative controls to exclude genomic contamination. Primer sequences are shown in Table 1.

2.5. In situ hybridization. In situ hybridization was performed using a digoxigenin (DIG)-labeled or a fluorescein-labeled riboprobe, as previously described (Yoshida et al. 2006). Each cDNA template probe (Table 2) was cloned by PCR with gene-specific primers, verified by sequencing, and used to produce a labeled riboprobe with the RNA Labeling kit (Roche). Coronal brain sections (thickness $10 \mu \mathrm{m}$ ) were cut on a cryostat, mounted onto slides, fixed in $4 \%$ paraformaldehyde, acetylated, and dehydrated prior to hybridization. For single-staining in situ hybridization, sections were hybridized with the DIG-labeled riboprobe. DIG was visualized using an alkaline phosphatase (AP)-conjugated anti-DIG antibody and BM purple substrate (Roche). For double-staining in situ hybridization, a fluorescein-labeled Fosb riboprobe was hybridized simultaneously with a DIG-labeled Adcyapl riboprobe. Fluorescein was visualized using an AP-conjugated anti-fluorescein antibody and the HNPP Fluorescent Detection Set (Roche), and DIG was visualized using an AP-conjugated anti-DIG antibody and BM purple substrate. The second colorization was performed after the detection of the first label and inactivation of $\mathrm{AP}$ in $\mathrm{PBS}$ at $75^{\circ} \mathrm{C}$ for $30 \mathrm{~min}$. None of the sense probes yielded any signal.

2.6. Immunohistochemical analysis. Sections (thickness, $30 \mu \mathrm{m}$ ) were cut with a cryostat and incubated with $3 \% \mathrm{H}_{2} \mathrm{O}_{2}$ for $1 \mathrm{~h}$. After blocking with $10 \%$ normal horse serum, the sections 
were incubated with polyclonal anti-rabbit c-Fos IgG (1:2000; Merck, Frankfurt, Germany) at $4^{\circ} \mathrm{C}$ overnight. The sections were then incubated with biotinylated anti-rabbit IgG secondary antibody (1:200; Vector, Burlingame, CA) for $1 \mathrm{~h}$ at room temperature, followed by a $1 \mathrm{~h}$ incubation with the $\mathrm{ABC}$ reagent (1:1000; Elite $\mathrm{ABC}$ Kit; Vector). Antigen detection was performed by using 3,3-diaminobenzidine (DAB) staining $(0.006 \%)$.

2.7. Immunoblot analysis. The isolated VMH was sonicated in protein lysis buffer containing protease inhibitor cocktail (Nacalai Tesque Inc., Japan) on ice, and then centrifuged at 20,000 $g$ for $10 \mathrm{~min}$ at $4^{\circ} \mathrm{C}$. Supernatants containing $15 \mu \mathrm{g}$ of protein were separated on $10 \%$ polyacrylamide gel and transferred onto polyvinyl difluoride membrane. The membrane was incubated with rabbit anti-BDNF polyclonal antibody (Santa Cruz, SC-546, diluted 1:200) at $4^{\circ} \mathrm{C}$ overnight. After washing, the membrane was incubated with horseradish peroxidase-conjugated secondary antibody for $1 \mathrm{~h}$ at room temperature, and bands were visualized with Chemi-Lumi One (Nacalai) and LAS-3000 (Fuji film, Japan). The same membrane was then stripped, and detection of $\beta$-actin was performed using mouse anti- $\beta$-actin monoclonal antibody (Millipore MAB1501R, diluted 1:3000) in the same way.

2.8. Assessment of food intake and body weight. Mice were individually housed for at least 3 days prior to starting ECS treatment. The mice were fed either a regular diet $(3.59 \mathrm{kcal} / \mathrm{g}$; Oriental Yeast, Japan) or a high-fat diet (HFD), with fat accounting for $60 \%$ of the total calories (5.24 kcal/g, no. D12492; Research Diets, New Brunswick, NJ). ECS was administered every other day ( 3 or 4 times in a week) for 35 days. Food intake was measured from 7:00 P.M. to 9:00 A.M. on days 1, 21, 28, and 32, and the caloric value of the food consumed was calculated. ECS was administered 3-4 h before measuring food intake. Body weight was measured 2-3 times each week. 
2.9. Hypothalamic destruction by gold thioglucose treatment. Mice were injected intraperitoneally with a single dose of $0.3 \mathrm{mg} / \mathrm{g}$ gold thioglucose (GTG; Wako, Japan) in saline, 1 week before starting either ECS or sham treatment.

2.10. Statistical Analyses. All data are presented as mean \pm S.E.M., and experiments with 2 groups were compared using an unpaired Student's $t$-test, while experiments with 3 or more groups were subjected to one- or two-way ANOVA, followed by the Bonferonni or Dunnett's post hoc test. Significance marks in figures are based on results from $t$-tests, Bonferonni or Dunnett's post hoc tests. The threshold for statistical significance was set at $p<0.05$. All analyses were performed using PRISM 5 software (Graphpad, San Diego, CA). 


\section{Results}

\subsection{The potential for c-Fos induction in the VMH persists after repeated ECS}

c-Fos is known as a neuronal activation marker, and previous research has shown that a single ECS stimulus induces c-Fos protein expression in rat VMH neurons (Jansson et al. 2006). Our first objective was to examine the effects of single and repeated ECS administration on c-Fos expression in the $\mathrm{VMH}$ and the dentate gyrus of the hippocampus in mice. c-Fos immunoreactivity (IR) was strongly induced in both the VMH and the dentate gyrus $2 \mathrm{~h}$ after a single ECS stimulus (Fig. 1B), which is consistent with previous data obtained from rats (Jansson et al. 2006). c-Fos-IR was decreased at $6 \mathrm{~h}$, and returned to basal levels $24 \mathrm{~h}$ after a single ECS stimulus (data not shown). For the repeated stimulation condition, ECS was administered once a day for 7 days (Fig. 1A). After 7 sets of ECS, c-Fos-IR was not detected in the dentate gyrus (Fig. 1B); this finding has also been previously reported in the rat hippocampus (Hsieh et al. 1998). In contrast, c-Fos-IR in the VMH was still prominent after repeated ECS stimuli (Fig. 1B). Although the staining intensity of c-Fos-IR after repeated ECS was weaker than that after a single ECS, the density of c-Fos-IR positive cells in the VMH was similar between single and repeated ECS stimuli (Fig. 1C). This result suggests that VMH neurons are activated by ECS, and the molecular effects of neural activation persist after repeated ECS.

To examine molecular changes in the VMH induced by single or repeated ECS stimuli, we next isolated the VMH from brain sections using laser-capture microdissection, and examined the gene expression changes. The dissected VMH and the residual brain sections from a typical microdissection are shown in Figure 2. To confirm the gene expression changes induced by ECS in the dissected VMH samples, we examined the expression of the fos and jun families of immediate-early genes, which are induced rapidly but transiently in the brain in response to various stimuli, including ECS (Hsieh et al. 1998). A single ECS treatment robustly induced the expression of Fos $\left(\mathrm{c}-\mathrm{Fos} ; t_{(6)}=4.412, p<0.01\right)$, 
Fosb $\left(\right.$ FosB; $\left.t_{(6)}=4.95, p<0.01\right)$, and Jun (c-Jun; $\left.t_{(6)}=4.41, p<0.01\right)$ in the VMH $2 \mathrm{~h}$ after stimulation (Fig. 3A-C). Even when 7 ECS treatments were administered, significant increases in expression levels in Fos ( $p<0.01$ for Dunnett's test following one-way ANOVA $\left.\left(F_{(3,8)}=36.04\right)\right), F o s b\left(p<0.01\right.$ for Dunnett's test following one-way ANOVA $\left.\left(F_{(3,8)}=54.41\right)\right)$, and Jun ( $p<0.01$ for Dunnett's test following one-way ANOVA $\left(F_{(3,8)}=27.86\right)$ ) were observed $2 \mathrm{~h}$ after the final stimulation, even though the extent of the induction was weaker than that measured after a single ECS treatment (Fig. 3A-C). The induction of these genes was transient, decreased after $6 \mathrm{~h}$, and returned to sham levels $24 \mathrm{~h}$ after the seventh ECS treatment. Since a previous study had shown the induction of $\operatorname{Rgs}_{s}$ (regulator of G protein signaling 4) in the rat VMH following both single and repeated ECS treatments (Gold et al. 2002), we also examined changes in the expression of $R g s 4$, and confirmed a similar induction pattern for this gene as for the immediate-early genes in the mouse VMH (a single ECS, $t_{(6)}=6.18, p<0.01 ; 7$ ECS, $p<0.05$ for Dunnett's test following one-way ANOVA $\left(F_{(3,8)}=6.02\right)$; Fig. 3D).

\subsection{ECS increases the expression of genes in the VMH involved in the suppression of food intake}

To explore the possible effects of ECS in the $\mathrm{VMH}$, we examined changes in the expression of several genes that have been suggested to play important roles in the VMH by qPCR analysis following repeated ECS treatments. We found that the expression levels of 4 genes, Adcyapl (PACAP), Bdnf (BDNF), Hrhl (Histamine receptor type 1; H1 receptor), and Crhr2 (corticotropin releasing hormone receptor 2; CRFR2) increased in the VMH following ECS. These genes have been previously suggested to have an anorexigenic effect when expressed in the VMH (Sakata et al. 1988; Unger et al. 2007; Hawke et al. 2009, Chao et al. 2012). The gene expression levels of Adcyapl, Bdnf, and Hrhl were significantly increased in the VMH $2 \mathrm{~h}$ after both a single and 7 treatments of ECS (Fig. 4A-C; Adcyapl, a single ECS, $t_{(6)}=6.98$, 
$p<0.01 ; 7$ ECS, $p<0.05$ for Dunnett's following one-way ANOVA $\left(F_{(3,8)}=5.86\right) ; B d n f$, a single ECS, $t_{(6)}=4.52, p<0.01 ; 7 \mathrm{ECS}, p<0.05$ for Dunnett's following one-way ANOVA $\left(F_{(3,8)}=4.45\right) ; H r h 1$, a single ECS, $t_{(6)}=15.14, p<0.01 ; 7$ ECS, $p<0.05$ for Dunnett's following one-way ANOVA $\left.\left(F_{(3,6)}=6.02\right)\right)$. The induction of Adcyapl and Bdnf persisted $6 \mathrm{~h}$ and $24 \mathrm{~h}$ after the seventh ECS treatment, while the increase of Hrhl was found to be transient, and returned to the sham level $24 \mathrm{~h}$ after completion of repeated ECS. The expression level of Crhr2 was significantly increased at $6 \mathrm{~h}$ and $24 \mathrm{~h}$ after the seventh ECS treatment, but not $2 \mathrm{~h}$ after a single, or 7 treatments of ECS (Fig. 4D; 7 ECS, $p<0.05$ for Dunnett's following one-way ANOVA $\left.\left(F_{(3,8)}=14.61\right)\right)$. Analysis of the BDNF immunoblot from the mediobasal hypothalamus, which includes the $\mathrm{VMH}$ region, demonstrated a significant increase in the protein level $6 \mathrm{~h}$ after the seventh ECS treatment $\left(\right.$ Fig. $4 \mathrm{E}, t_{(7)}=$ $3.29, p<0.05)$.

We next performed in situ hybridization to provide further confirmation of the expression site of these genes within the hypothalamus. Although Fosb expression signals were observed after ECS throughout the hypothalamus, the signal was the most dense in the VMH (Fig. 5A). In contrast, a single, or 7 treatments of ECS rarely induced Fosb expression in the ARC (Fig. 5A), suggesting that the neurons of the $\mathrm{VMH}$ than the ARC are more directly activated by ECS treatment. Under the sham condition, the low level of expression signal in Rgs4, Adcyapl, and Bdnf was detected in the VMH. However, more intense signal was observed after both single and repeated ECS (Fig. 5A, B). The Hrhl signal after ECS was localized mainly in the dorsomedial region of the VMH. We further examined the co-localization of Fosb (as a neuronal activation marker) with Adcyapl signals. Most of the Adcyapl signal was co-localized with the Fosb signal (Fig. 5C, yellow arrows), while there appeared to be some cells showing only the Fosb signal (Fig. 5C, white arrows).

\subsection{Repeated ECS treatments lead to decreased food intake and body weight gain}


Since PACAP, BDNF, H1 receptor, and CRFR2 signals in the VMH have all been suggested to have anorexigenic effects (Sakata et al. 1988; Unger et al. 2007; Hawke et al. 2009; Chao et al. 2012), we hypothesized that ECS treatment influences feeding behavior. To examine the effect of ECS on food intake and body weight gain, mice were isolated in a single cage, and fed either a regular diet or HFD, beginning 3 days prior to either sham or ECS treatment. ECS or sham treatment was administered every other day for 35 days (Fig. 6A). After the first ECS administration, food intake was found to be no different between the sham and ECS mice in both the regular diet and HFD groups (regular diet, $t_{(14)}=0.001, p>0.05$; HFD, $t_{(12)}=$ 0.74, $p>0.05$; Fig. 6B, C), suggesting that a single ECS stimulus did not affect feeding behavior. However, after more than 10 ECS treatments, food intake was significantly decreased in both the regular diet and HFD groups of ECS-treated mice compared to sham-treated mice (regular diet, $F_{(1,42)}=20.44$ for the main ECS effect, $p<0.01 ; \mathrm{HFD}, F_{(1,22)}$ $=10.26$ for the main ECS effect, $p<0.01$; Fig. 6B, C). We also monitored body weight over the course of the experiment. Although calorie intake was similar between the regular diet and HFD groups, weight gain over time in the HFD group was higher than in the regular diet group. Repeated ECS treatments had a significant suppressive effect on body weight gain in both groups (regular diet, $F_{(1,84)}=30.83$ for the main ECS effect, $p<0.01$; HFD, $F_{(1,66)}=5.90$ for the main ECS effect, $p<0.05$; Fig. 6D, E). We also examined the suppressive effect of ECS on body weight gain in genetically obese, leptin-deficient ob/ob mice, and in these animals, repeated ECS treatments again had a significant suppressive effect on body weight gain $\left(F_{(1,20)}=17.04\right.$ for the main ECS effect, $p<0.01$; Fig. $\left.6 F\right)$. These results suggest that repeated ECS treatments produce an anorexigenic effect and reduce body weight gain, regardless of diet nutritional value or leptin status.

\subsection{VMH and ARC activation is required for the anorexigenic effect induced by repeated ECS}


In the hypothalamus, neurons in the $\mathrm{VMH}$, as well as pro-opiomelanocortin (POMC) neurons in the ARC, mediate anorexigenic signals. A recent study also showed that the neurons in the VMH project their excitatory inputs to anorexigenic POMC neurons in the ARC (Sternson et al. 2005), suggesting that the activation of $\mathrm{VMH}$ neurons increases the activity of anorexigenic POMC neurons. We next examined whether or not the activation of the VMH and ARC signal is required for the ECS-induced anorexigenic effects to occur. Treatment with GTG, which is taken up by, and is selectively toxic to glucose-sensitive neurons in the $\mathrm{VMH}$ and $\mathrm{ARC}$, results in chemical lesions of the $\mathrm{VMH}$ and $\mathrm{ARC}$, with the subsequent development of hyperphagia and obesity (Marshall et al.1956; Debons et al. 1977). GTG was administered intraperitoneally, and 3 weeks later, hypothalamic lesion was confirmed by the reduced expression of $\mathrm{Nr} 5 \mathrm{al}$ (steroidogenic factor 1; SF-1), which has been validated as a VMH marker (Kim et al. 2009), and Pomc, as a marker of anorexigenic POMC neurons in the ARC, by in situ hybridization (Fig. 7A). When ECS was administered to GTG-treated mice, the induction of Fosb was also reduced in the VMH-lesioned area, but not in the nearby piriform cortex (Fig. 7B), suggesting that specific hypothalamic lesions, including the VMH, were caused by the GTG treatment. We also examined the expression of Npy in the ARC, because NPY neurons mediate orexigenic signals in the ARC. However, the NPY cell population in the ARC appeared intact (data not shown), suggesting the retention of NPY-positive neurons of the ARC in GTG-treated mice under our test conditions.

ECS administration was started 1 week after GTG treatment, and given every other day for 35 days. The increased food intake and weight gain were most prominent around day 7 (i.e., 14 days after GTG treatment) in the GTG-treated mice (Fig. 7C, D). However, food intake and weight gain was not significantly different between the sham and ECS groups in GTG-treated mice over the course of the experiment (weight gain, $F_{(1,40)}=0.23$ for the main ECS effect, $p>0.05$; food intake, $t_{(8)}=1.59, p>0.05$ on day 20; Fig. 7C, D). This result suggests that the activation of the VMH and/or ARC neurons is required for the ECS-induced 
anorexigenic effects. 
Segi-Nishida et al.

\section{Discussion}

$\mathrm{VMH}$ is the hypothalamic region that has been implicated in the regulation of numerous physiological functions, including sexual behavior, mood regulation, energy homeostasis, and thermogenesis (McClellan et al. 2006). Although it has been shown that ECS treatment induces the proliferation of endothelial cells, as well as neuronal activation in the VMH (Jansson et al. 2006), the molecular changes and functional effects of ECS in the VMH remain unknown. Here, we demonstrate that ECS increases the expression of Bdnf, Adcyapl, $H r h 1$, and Crhr2 genes, which are implicated in the anorexigenic effect mediated by the VMH. We showed that repeated ECS treatments led to decreased food intake and body weight gain, and that this effect depends on VMH and/or ARC function. These findings demonstrate the activation of the anorexigenic signal in the VMH by ECS, and suggest that ECS-induced anorexigenic behavior is mediated by hypothalamic activity, including VMH activity.

\subsection{ECS-induced gene expression changes in the VMH}

In this study, we identified several genes that responded to ECS stimulation in the VMH. Notably, ECS induced the expression of Bdnf, Adcyapl, Hrhl, and Crhr2 in the VMH. BDNF is highly expressed in several energy balance centers, including the VMH. Fasting signals decrease the expression of $B d n f$ in the $\mathrm{VMH}$, and conversely, leptin signals or glucose administration increase Bdnf expression (Xu et al. 2003; Komori et al. 2006; Unger et al. 2007). Furthermore, deletion of the $B d n f$ gene, specifically in the VMH and the adjacent dorsomedial hypothalamus, results in hyperphagia and obesity (Unger et al. 2007). Adcyapl (PACAP) is one of the VMH-enriched genes (Segal et al. 2005). Adcyapl mRNA expression can also be reduced by fasting, and this effect can be prevented by leptin treatment (Hawke et al. 2009). In addition, PACAP administration intracerebroventricularly, or directly into the $\mathrm{VMH}$, results in decreased food intake, with an accompanied increase in energy expenditure 
(Hawke et al. 2009; Resch et al. 2011). Histamine signals have also been thought to have an anorexigenic effect, since some antipsychotics with antihistamine activity stimulate food intake and body weight gain. Pharmacological blockade of $\mathrm{H} 1$ receptors in the VMH elicits feeding behavior (Sakata et al. 1988), and, as measured electrophysiologically, histamine elicits excitatory responses via the $\mathrm{H} 1$ receptor in VMH neurons (Zhou et al. 2007). Urocortin 3 is an anorexigenic neuropeptide with a high affinity for CRFR2. The expression of CRFR2 mRNA was decreased in the rat VMH following food deprivation (Poulin et al. 2012), and mice with reduced CRFR2 expression in the VMH exhibited elevated basal feeding (Chao et al. 2012). Taken together, our data suggest that ECS treatment stimulates the production of BDNF and PACAP, as well as signaling of histamine H1 and CRFR2, and thus stimulates satiety signals in the VMH.

However, it should be noted that we only observed reduced food intake behavior after repeated ECS, but not single ECS stimulus, while some of genes encoding the above anorexigenic factors had already been induced after a single ECS. The reasons for this temporal difference between gene expression and the anorexigenic behavior remain unknown. One possibility is that the repeated activation of anorexigenic signaling in the VMH by chronic ECS is necessary to evoke the reduced food intake behavior. Further studies are required to elucidate the differences in responsiveness between a single and repeated ECS in the VMH. A further possibility is that ECS also affects other anorexigenic signal pathways in the VMH. One such potential candidate is the leptin signaling system, because this signal pathway in the $\mathrm{VMH}$, as well as in the ARC, is known to be important in the control of food intake and energy expenditure (Dhillon et al. 2006; Bingham et al. 2008). We examined the effect of ECS treatment on the expression of leptin receptors (Leprl); however, the expression was not changed by either single or repeated ECS administration (data not shown). Moreover, leptin-deficient ob/ob mice still exhibited the decreased body weight gain induced 
by repeated ECS, suggesting that the ECS-induced anorexigenic signal in the VMH is independent of leptin action.

\subsection{Suppressive effect of repeated ECS treatment on food intake mediated by VMH/ARC activation}

In this study, we clearly showed that repeated ECS treatment leads to decreased food intake under both the regular diet and HFD conditions. A small number of studies examined the effect of ECS on food intake more than 30 years ago. However, these studies focused on the effects of a single ECS treatment, and the results obtained were inconsistent (Prewett et al. 1977; Walker et al. 1981). Here, we demonstrated that GTG-induced VMH and ARC lesions abolished the suppressive effects of repeated ECS treatments on food intake. This finding indicates that activation of the $\mathrm{VMH}$ and/or ARC is necessary for the decreased food intake induced by ECS.

Administration of GTG to adult mice produces a hypothalamic lesion, encompassing the $\mathrm{VMH}$ and $\mathrm{ARC}$, and leads to hyperphagia and obesity (Marshall et al. 1955; Debons et al. 1977). In fact, the expression of Nr5al (SF-1) mRNA in the VMH-lesioned area, and Pomc mRNA in the ARC-lesioned area was dramatically attenuated in the GTG-treated mice (Fig. 7). As POMC neurons in the ARC play an important role in inhibiting feeding, we cannot rule out the possibility that ECS directly activates anorexigenic signals in the ARC. However, as the Fosb expression induced by ECS is mainly observed in the $\mathrm{VMH}$, not in the ARC, it seems that ECS directly activates the neurons of the VMH, rather than the ARC. However, since POMC neurons in the ARC receive excitatory input from the VMH (Sternson et al. 2005), anorexigenic signals in the ARC may be also indirectly activated via this excitatory input from the VMH evoked by ECS. To clarify the mechanisms involved, it may prove important to define the molecular changes that take place in the ARC after repeated ECS treatment. 


\subsection{Effect of repeated ECS on body weight and antidepressant-like behavior}

In this study, we also demonstrated that repeated ECS treatment suppresses body weight gain in mice fed either a regular diet or HFD, a finding of which was repeated in ob/ob mice. Body weight gain is regulated by the balance between calorie intake and energy expenditure. Related to this, previous studies have been demonstrated that repeated ECS treatment reduced immobility time in the FST (Porsolt et al. 1977; Li et al. 2006), and 1 group also showed that repeated ECS treatment increased locomotor activity in the open field test (Hidaka et al. 2008). These results suggest that ECS treatment increases energy expenditure under stressful conditions. Although the precise effects of ECS on energy expenditure, including spontaneous locomotor activity, metabolic rate, and $\mathrm{O}_{2}$ consumption remain unknown, our results suggest a potential application for ECS as an obesity treatment. One case report showed that obese patients with mood disorders experienced significant weight loss after ECS treatment (Moss et al. 2006). It is possible that ECS, or other brain stimulation protocols, such as transcranial magnetic stimulation, act to reduce body weight or normalize eating behavior in obese patients through VMH activation (Halpern et al. 2008; Melega et al. 2012).

\section{Conclusion}

In this study, we have identified molecular changes in the VMH caused by ECS treatment, and demonstrated an anorexigenic effect of ECS mediated by VMH activation. ECS is a highly effective therapy for a number of psychiatric diseases, including depression, but it also has implicated beneficial effects in other neurological diseases, e.g., alleviation of the motor symptoms of Parkinson's disease and of the hyperalgesia component of neuropathic pain (Popeo et al. 2009; Abdi et al. 2004). However, due to a lack of mechanistic evidence, ECS has not gained acceptance as a clinical treatment option for these conditions. This study suggests that ECS could also act to reduce body weight or normalize eating behaviors in 
obese patients through VMH activation. Our data provide new insights into potential avenues for anti-obesity therapy.

\section{Acknowledgements}

This work was supported in part by MEXT KAKENHI Grant Number 21790074, 23790084 (E. S-N), grants from the Takeda Science Foundation (E. S-N), The Naito Foundation (E. S-N), and Astellas Foundation (E. S-N), and a grant from the Funding Program for Next Generation World-Leading Researchers (Y. O.). We thank Dr. Tomoyuki Furuyashiki for helpful discussion. The authors declare that they have no conflicts of interest. 
Segi-Nishida et al.

\section{References}

Abdi, S., Haruo, A., Bloomstone, J., 2004. Electroconvulsive therapy for neuropathic pain: a case report and literature review. Pain Physician 7, 261-263.

Bingham, N. C., Anderson, K. K., Reuter, A. L., Stallings, N. R., Parker, K. L., 2008. Selective loss of leptin receptors in the ventromedial hypothalamic nucleus results in increased adiposity and a metabolic syndrome. Endocrinology 149, 2138-2148.

Chao, H., Digruccio, M., Chen, P., Li, C., 2012. Type 2 corticotropin-releasing factor receptor in the ventromedial nucleus of hypothalamus is critical in regulating feeding and lipid metabolism in white adipose tissue. Endocrinology 153, 166-176.

Debons, A. F., Krimsky, I., Maayan, M. L., Fani, K., Jemenez, F. A., 1977. Gold thioglucose obesity syndrome. Fed Proc 36, 143-147.

Dhillon, H., Zigman, J. M., Ye, C., Lee, C. E., McGovern, R. A., Tang, V., Kenny, C. D., Christiansen, L. M., White, R. D., Edelstein, E. A., Coppari, R., Balthasar, N., Cowley, M. A., Chua, S., Jr., Elmquist, J. K., Lowell, B. B., 2006. Leptin directly activates SF1 neurons in the $\mathrm{VMH}$, and this action by leptin is required for normal body-weight homeostasis. Neuron 49, 191-203.

Elmquist, J. K., Coppari, R., Balthasar, N., Ichinose, M., Lowell, B. B., 2005. Identifying hypothalamic pathways controlling food intake, body weight, and glucose homeostasis. J Comp Neurol 493, 63-71.

Franklin, K. B. J., and Paxinos, G., 2008. The Mouse Brain in Stereotaxic Coordinates. 3rd edition, Elsevier Academic Press, San Diego.

Gold, S. J., Heifets, B. D., Pudiak, C. M., Potts, B. W., Nestler, E. J., 2002. Regulation of regulators of $\mathrm{G}$ protein signaling mRNA expression in rat brain by acute and chronic electroconvulsive seizures. J Neurochem $82,828-838$. 
Halpern, C. H., Wolf, J. A., Bale, T. L., Stunkard, A. J., Danish, S. F., Grossman, M., Jaggi, J. L., Grady, M. S., Baltuch, G. H., 2008. Deep brain stimulation in the treatment of obesity. J Neurosurg 109, 625-634.

Hawke, Z., Ivanov, T. R., Bechtold, D. A., Dhillon, H., Lowell, B. B., Luckman, S. M., 2009. PACAP neurons in the hypothalamic ventromedial nucleus are targets of central leptin signaling. J Neurosci 29, 14828-14835.

Hidaka, N., Suemaru, K., Li, B., Araki, H., 2008. Effects of repeated electroconvulsive seizures on spontaneous alternation behavior and locomotor activity in rats. Biol Pharm Bull 31, 1928-1932.

Hsieh, T. F., Simler, S., Vergnes, M., Gass, P., Marescaux, C., Wiegand, S. J., Zimmermann, M., Herdegen, T., 1998. BDNF restores the expression of Jun and Fos inducible transcription factors in the rat brain following repetitive electroconvulsive seizures. Exp Neurol 149, 161-174.

Jansson, L., Hellsten, J., Tingstrom, A., 2006. Region specific hypothalamic neuronal activation and endothelial cell proliferation in response to electroconvulsive seizures. Biol Psychiatry 60, 874-881.

Kim, K. W., Zhao, L., Parker, K. L., 2009. Central nervous system-specific knockout of steroidogenic factor 1. Mol Cell Endocrinol 300, 132-136.

King, B. M., 2006. The rise, fall, and resurrection of the ventromedial hypothalamus in the regulation of feeding behavior and body weight. Physiol Behav 87, 221-244.

Komori, T., Morikawa, Y., Nanjo, K., Senba, E., 2006. Induction of brain-derived neurotrophic factor by leptin in the ventromedial hypothalamus. Neuroscience 139, 1107-1115.

Li, B., Suemaru, K., Cui, R., Kitamura, Y., Gomita, Y., Araki, H., 2006. Repeated electroconvulsive stimuli increase brain-derived neurotrophic factor in ACTH-treated rats. Eur J Pharmacol 529, 114-121. 
Majdic, G., Young, M., Gomez-Sanchez, E., Anderson, P., Szczepaniak, L. S., Dobbins, R. L., McGarry, J. D., Parker, K. L., 2002. Knockout mice lacking steroidogenic factor 1 are a novel genetic model of hypothalamic obesity. Endocrinology 143, 607-614.

Marshall, N. B., Mayer, J., 1956. Specificity of gold thioglucose for ventromedial hypothalamic lesions and hyperphagia. Nature 178, 1399-1400.

McClellan, K. M., Parker, K. L., Tobet, S., 2006. Development of the ventromedial nucleus of the hypothalamus. Front Neuroendocrinol 27, 193-209.

Melega, W. P., Lacan, G., Gorgulho, A. A., Behnke, E. J., De Salles, A. A., 2012.

Hypothalamic deep brain stimulation reduces weight gain in an obesity-animal model. PLoS One 7, e30672.

Moellentine, C., Rummans, T., Ahlskog, J. E., Harmsen, W. S., Suman, V. J., O'Connor, M. K., Black, J. L., Pileggi, T., 1998. Effectiveness of ECT in patients with parkinsonism. J Neuropsychiatry Clin Neurosci 10, 187-193.

Moss, L. E., Vaidya, N. A., 2006. Electroconvulsive therapy as an alternative treatment for obese patients with mood disorders. J Ect 22, 223-225.

Pagnin, D., de Queiroz, V., Pini, S., Cassano, G. B., 2004. Efficacy of ECT in depression: a meta-analytic review. J Ect 20, 13-20.

Popeo, D., Kellner, C. H., 2009. ECT for Parkinson's disease. Med Hypotheses 73, 468-469.

Porsolt, R. D., Anton, G., Blavet, N., Jalfre, M., 1978. Behavioural despair in rats: a new model sensitive to antidepressant treatments. Eur J Pharmacol 47, 379-391.

Poulin, A. M., Lenglos, C., Mitra, A., Timofeeva, E., 2012. Hypothalamic expression of urocortin 3 and the type 2 corticotropin-releasing factor receptor is regulated according to feeding state in lean but not obese Zucker rats. Neuropharmacology 63, 147-153.

Prewett, M. J., Milner, J. S., 1977. Effects of electroconvulsive shock on food and water intake in the rat. Physiol Behav 19, 341-343. 
Resch, J. M., Boisvert, J. P., Hourigan, A. E., Mueller, C. R., Yi, S. S., Choi, S., 2011. Stimulation of the hypothalamic ventromedial nuclei by pituitary adenylate cyclase-activating polypeptide induces hypophagia and thermogenesis. Am J Physiol Regul Integr Comp Physiol 301, R1625-1634.

Sakata, T., Ookuma, K., Fukagawa, K., Fujimoto, K., Yoshimatsu, H., Shiraishi, T., Wada, H., 1988. Blockade of the histamine H1-receptor in the rat ventromedial hypothalamus and feeding elicitation. Brain Res 441, 403-407.

Santarelli, L., Saxe, M., Gross, C., Surget, A., Battaglia, F., Dulawa, S., Weisstaub, N., Lee, J., Duman, R., Arancio, O., Belzung, C., Hen, R., 2003. Requirement of hippocampal neurogenesis for the behavioral effects of antidepressants. Science 301, 805-809.

Segal, J. P., Stallings, N. R., Lee, C. E., Zhao, L., Socci, N., Viale, A., Harris, T. M., Soares, M. B., Childs, G., Elmquist, J. K., Parker, K. L., Friedman, J. M., 2005. Use of laser-capture microdissection for the identification of marker genes for the ventromedial hypothalamic nucleus. J Neurosci 25, 4181-4188.

Segi-Nishida, E., 2011. Exploration of new molecular mechanisms for antidepressant actions of electroconvulsive seizure. Biol Pharm Bull 34, 939-944.

Shirayama, Y., Chen, A. C., Nakagawa, S., Russell, D. S., Duman, R. S., 2002.

Brain-derived neurotrophic factor produces antidepressant effects in behavioral models of depression. J Neurosci 22, 3251-3261.

Sternson, S. M., Shepherd, G. M., Friedman, J. M., 2005. Topographic mapping of VMH --> arcuate nucleus microcircuits and their reorganization by fasting. Nat Neurosci 8 , 1356-1363.

Sutor, B., Rasmussen, K. G., 2008. Electroconvulsive therapy for agitation in Alzheimer disease: a case series. J ECT 24, 239-241. 
Unger, T. J., Calderon, G. A., Bradley, L. C., Sena-Esteves, M., Rios, M., 2007. Selective deletion of Bdnf in the ventromedial and dorsomedial hypothalamus of adult mice results in hyperphagic behavior and obesity. J Neurosci 27, 14265-14274.

Walker, M. K., Gumm, W. B., Day, H. D., 1981. Electroconvulsive shock effects on food and water intake as a function of prior deprivational state. Physiol Behav 27, 171-173.

Xu, B., Goulding, E. H., Zang, K., Cepoi, D., Cone, R. D., Jones, K. R., Tecott, L. H., Reichardt, L. F., 2003. Brain-derived neurotrophic factor regulates energy balance downstream of melanocortin-4 receptor. Nat Neurosci 6, 736-742.

Yoshida, S., Sukeno, M., Nakagawa, T., Ohbo, K., Nagamatsu, G., Suda, T., Nabeshima, Y., 2006. The first round of mouse spermatogenesis is a distinctive program that lacks the self-renewing spermatogonia stage. Development 133, 1495-1505.

Zhou, J., Lee, A. W., Devidze, N., Zhang, Q., Kow, L. M., Pfaff, D. W., 2007. Histamine-induced excitatory responses in mouse ventromedial hypothalamic neurons: ionic mechanisms and estrogenic regulation. J Neurophysiol 98, 3143-3152. 
Segi-Nishida et al.

\section{Figure Legends}

Figure 1 The effect of single or repeated ECS treatment on c-Fos expression in the VMH and hippocampus. (A) Design of experiments for expression studies (From Figure 1 to Figure 5). Arrowheads show ECS treatment. Control group was sham-handled in the same manner as the ECS group, but without ECS administration. Arrows indicate sampling points. (B) Immunohistochemical staining of c-Fos in the VMH and hippocampus (Hippo) $2 \mathrm{~h}$ after sham (1st) or ECS (1st or 7th) treatments. Brown dots represent c-fos positive cells. (C) Enlarged photographs of c-Fos staining in the VMH $2 \mathrm{~h}$ after the 1st or 7th ECS treatment. Scale bars: A, $200 \mu \mathrm{m} ; \mathrm{B}, 30 \mu \mathrm{m}$.

Figure 2 Laser microdissection of the VMH. (A and B) Coronal section of the mouse brain containing the hypothalamus before microdissection. (C) The tissue of the VMH attached to film melted by laser. (D) The section remaining after removal of the VMH. Scale bar: 200 $\mu \mathrm{m}$.

Figure 3 ECS-induced gene expression involved in neuronal activation in the VMH. Fos (A), Fosb (B), Jun (C), and Rgs4 (D) mRNA expression was examined in the isolated VMH from sham- and ECS-treated mice. The brains were obtained $2 \mathrm{~h}$ after the 1st ECS treatment, or 2, 6, and $24 \mathrm{~h}$ after the 7th ECS treatment. The amount of each mRNA was normalized to that of 18S RNA, and an arbitrary unit (a.u.) was defined with the value of the VMH from the 1st or 7 th sham-treated mice group as 1 . Results are expressed as mean \pm SEM ( $n=3$ or 4 ) with * indicating significant differences $(p<0.05)$ compared to sham control for unpaired $t$-test (Sham-1st vs ECS-1st), or post hoc Dunnett's multiple comparison tests after one-way ANOVA (Sham-7th vs ECS-7th).

Figure 4 ECS-induced expression changes involved in anorexigenic actions in the VMH. 
Adcyapl (A), Bdnf (B), Hrhl (C), and Crhr2 (D) mRNA expression was examined in the VMH from sham- or ECS-treated mice. The brains were obtained $2 \mathrm{~h}$ after the 1 st ECS treatment, or 2, 6, and $24 \mathrm{~h}$ after the 7th ECS treatment. The amount of each mRNA was normalized to that of $18 \mathrm{~S}$ RNA, and an arbitrary unit (a.u.) was defined with the value of the VMH from the 1 st or 7 th sham-treated mice group as 1 . Results are expressed as mean \pm SEM $(\mathrm{n}=3$ or 4$)$ with $*$ indicating significant differences $(p<0.05)$ compared to sham control for unpaired $t$-test (Sham-1st vs ECS-1st) or post hoc Dunnett's multiple comparison tests after one-way ANOVA (Sham-7th vs ECS-7th). (E) The expression of BDNF protein was examined in the mediobasal hypothalamus, which includes the VMH region. Mediobasal hypothalami were harvested $6 \mathrm{~h}$ after the 7 th-ECS or 7 th-sham treatments. Immunoblot analysis for BDNF or $\beta$-actin, and densitometric analysis of the blots are shown. Results are expressed as mean \pm SEM $(n=4$ or 5$)$, with $*$ indicating a significant difference $(p<0.05)$ compared to the sham control, as determined with an unpaired $t$-test (Sham-7th vs ECS-7th).

Figure 5 In situ hybridization analysis of ECS-induced gene expression in the VMH. Brain sections containing the VMH were obtained from sham-treated animals, and from animals 2 $\mathrm{h}$ after the 1st ECS treatment, or $2 \mathrm{~h}$ after the 7th ECS treatment. DIG-labeled cRNA of Fosb, Rgs4, Adcyapl, Bdnf, and Hrhl were hybridized to the VMH sections (A and B). DIG was visualized using an alkaline phosphatase (AP)-conjugated anti-DIG antibody and BM purple substrate. Scale bar: $200 \mu \mathrm{m}$. (C) Double-staining for Fosb (red fluorescence, left; brown, right) and Adcyapl (purple, right). Yellow arrows indicate the co-localization of Fosb and Adcyapl signals. White arrows indicate cells in which only Fosb signal was detected. Scale bar: $40 \mu \mathrm{m}$.

Figure 6 The effect of ECS on weight gain and food intake. (A) Design of experiments. Mice were isolated in single cages and fed either a regular diet (RD) or high-fat diet (HFD) starting 
3 days before the first sham or ECS treatment. ECS or sham was administered 3 or 4 times in a week. (B and C) Food intake changes in sham- and ECS-treated mice $(n=6-8)$ on the RD (B) and on the HFD (C). On day 1, food intake was measured by calories consumed for $14 \mathrm{~h}$ during the dark cycle after the 1st ECS (D1). On days 21, 28, and 32, food intake was measured for $14 \mathrm{~h}$ during the dark cycle after the ECS. The average food intake is shown as calories (after D20). (D and E) Average body weight changes of sham- (open circles) and ECS (closed circles)-treated mice ( $n=6-8$ ) on the RD (D) and on the HFD (E). (F) Average body weight changes of sham- (open circles) and ECS (closed circles)-treated ob/ob mice (n $=3$ or 4$)$. Results are expressed as mean \pm SEM with $*$ indicating significant differences $(p<$ 0.05) compared to sham for post hoc Bonferroni's tests after two-way ANOVA (B and C) and for unpaired $t$-test (D and $\mathrm{E}$ ).

Figure 7 The effect of gold thioglucose (GTG)-induced hypothalamic lesions on ECS-induced hypophagia. (A) Expression of Nr5al (SF-1; dashed area), a VMH specific marker, and Pomc (arrows) in the hypothalamus of mice treated with GTG (3 weeks later). The VMH and arcuate area was lesioned by GTG treatment. (B) ECS-induced expression of Fosb in GTG-treated VMH (black arrowheads; upper) and piriform cortex (white arrowheads; lower). Scale bar: $200 \mu \mathrm{m}$. (C) The effect of chronic ECS on body weight and food intake in GTG-treated mice on the regular diet. GTG was intraperitoneally injected 7 days before ECS. Results are expressed as the mean \pm SEM $(n=5)$. NS, not significant, for post hoc Bonferroni's tests after two-way ANOVA (body weight changes) and for unpaired $t$-test (calorie consumption). 
Table 1 List of primers used for qPCR analysis

\begin{tabular}{lll}
\hline Gene & Forward primer $\left(5^{\prime}\right.$ to $\left.3^{\prime}\right)$ & Reverse primer $\left(5^{\prime}\right.$ to $\left.3^{\prime}\right)$ \\
\hline Fos & CTGTCAACACACAGGACTTTT & AGGAGATAGCTGCTCTACTTTG \\
Fosb & TTTTCCCGGAGACTACGACTC & GTGATTGCGGTGACCGTTG \\
Jun & CGCCAAGAACTCGGACCTTC & GGTCGGTGTAGTGGTGATGT \\
Rgs 4 & GGCTGAATCGTTGGAAAACCT & TCCTCGCTGTATTCCGACTTC \\
Adcyap1 & CGAGGCTTACGACCAGGAC & ATTTCGTGGGCGACATCTCTC \\
Bdnf & GACAAGGCAACTTGGCCTAC & ACTGTCACACACGCTCAGCTC \\
Hrhl & ATCCTGTGTATTGATCGCTACCG & GGGTCTTGGTTCGATACCTCA \\
Crhr2 & CCTGTGGACACTTTTGGAGCA & TGTTGCAGTAGGTGTAGGGAC \\
Lepr & ACCTGGCATATCCAATCTCTCC & TCGGTGGTCCACAAAACAACT \\
$18 S$ rRNA & GAGGCCCTGTAATTGGAATGAG & GCAGCAACTTTAATATACGCTATTGG \\
\hline
\end{tabular}

Table 2 List of primers used for making in situ probes

\begin{tabular}{lllc}
\hline Gene & Forward primer $\left(5^{\prime}\right.$ to $\left.3^{\prime}\right)$ & Reverse primer $\left(5^{\prime}\right.$ to $\left.3^{\prime}\right)$ & Length (bp) \\
\hline Fosb & ATGTTTCAAGCTTTTCCGG & TGAGGACAAACGAGGAAGTG & 919 \\
Rss 4 & ATGGCCTTCCCTCCTTTG & GGGAGCTCTGGGGACATT & 928 \\
Adcyapl & ACCATGTGTAGCGGAGCAAG & TGCTATTCGGCGTCCTTTGT & 515 \\
Bdnf & CGACGACATCACTGGCTG & CGGCAACAAACCACAACA & 824 \\
$H r h l$ & AGAGCATCTGAAAGAGACCCAG & GTTCTCATCCCAAGTTTCCAAG & 644 \\
Npy & GTGGATCTCTTCTCTCACAG & AACAACAAGGGAAATGGGGC & 502 \\
Pomc & GTTAAGAGCAGTGACTAAGAG & CCTAACACAGGTAACTCTAAG & 915 \\
Nr5al & ATCTACCGCCAGGTCCAGTAC & AGATAAATACCAGCCCAGCCAG & 1115 \\
\hline
\end{tabular}


A

Single ECS treatment

ECS
D1
if
$2 \mathrm{~h}$

7 sets of ECS treatment (once/day)
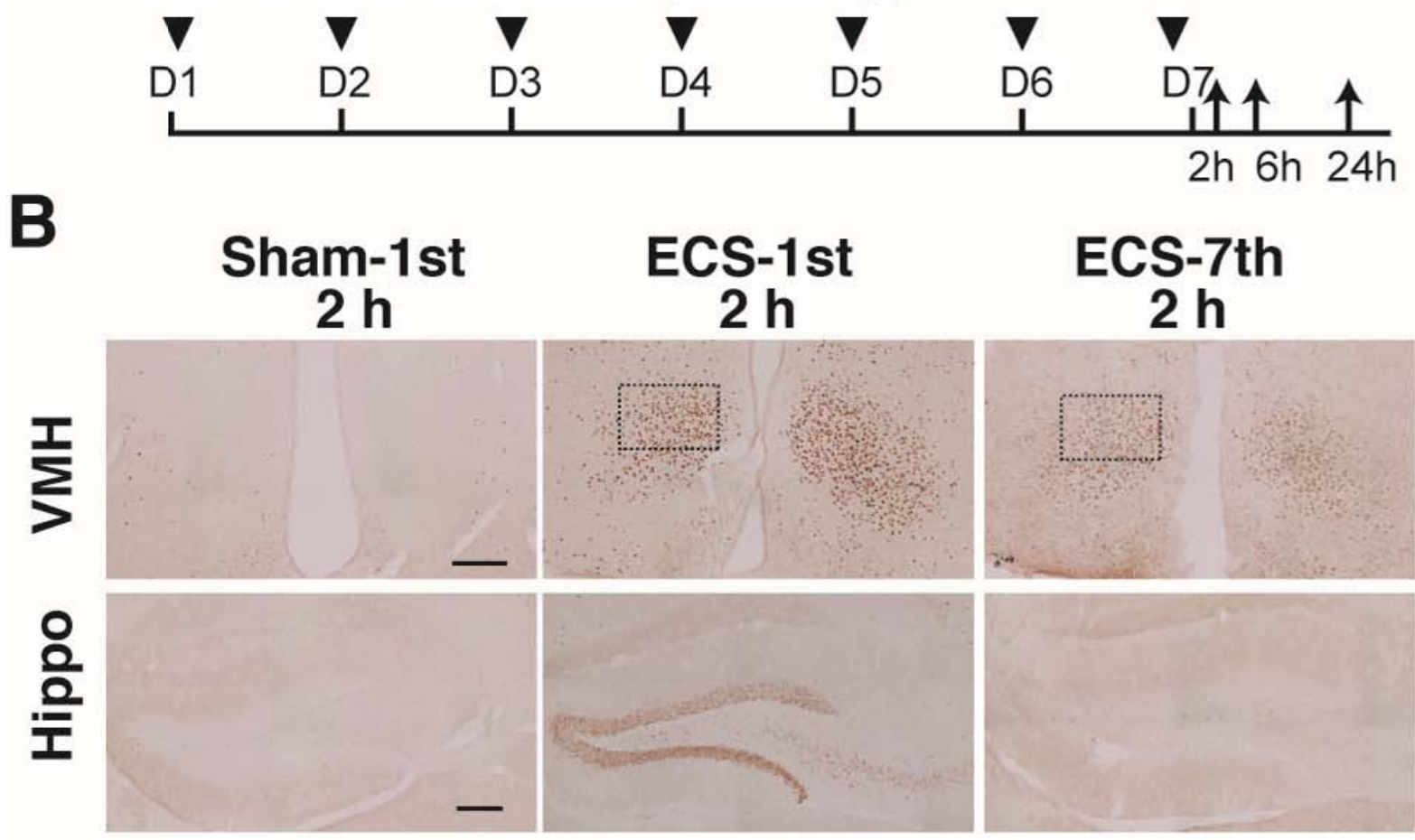

C ECS-1st

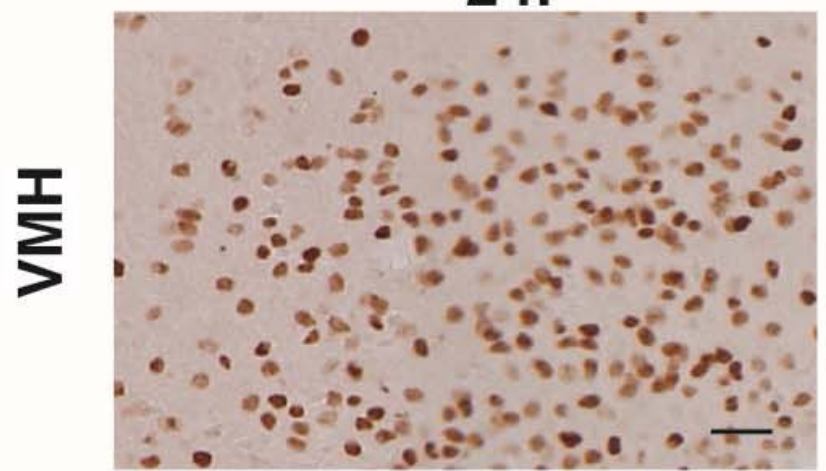

ECS-7th

$2 \mathrm{~h}$

Fig 1

Segi-Nishida et al.

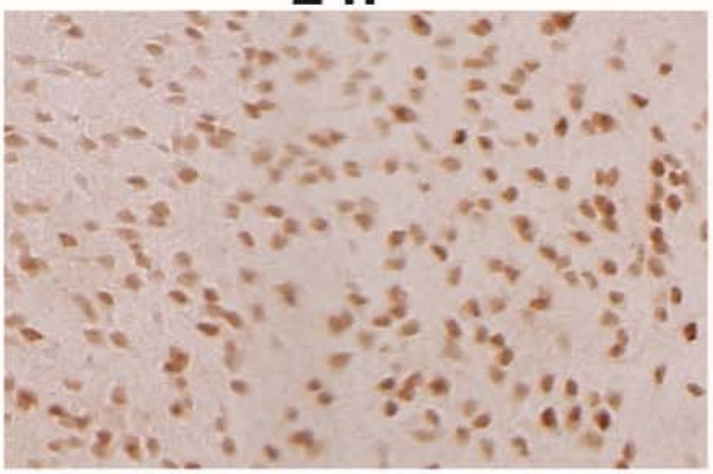


A

B

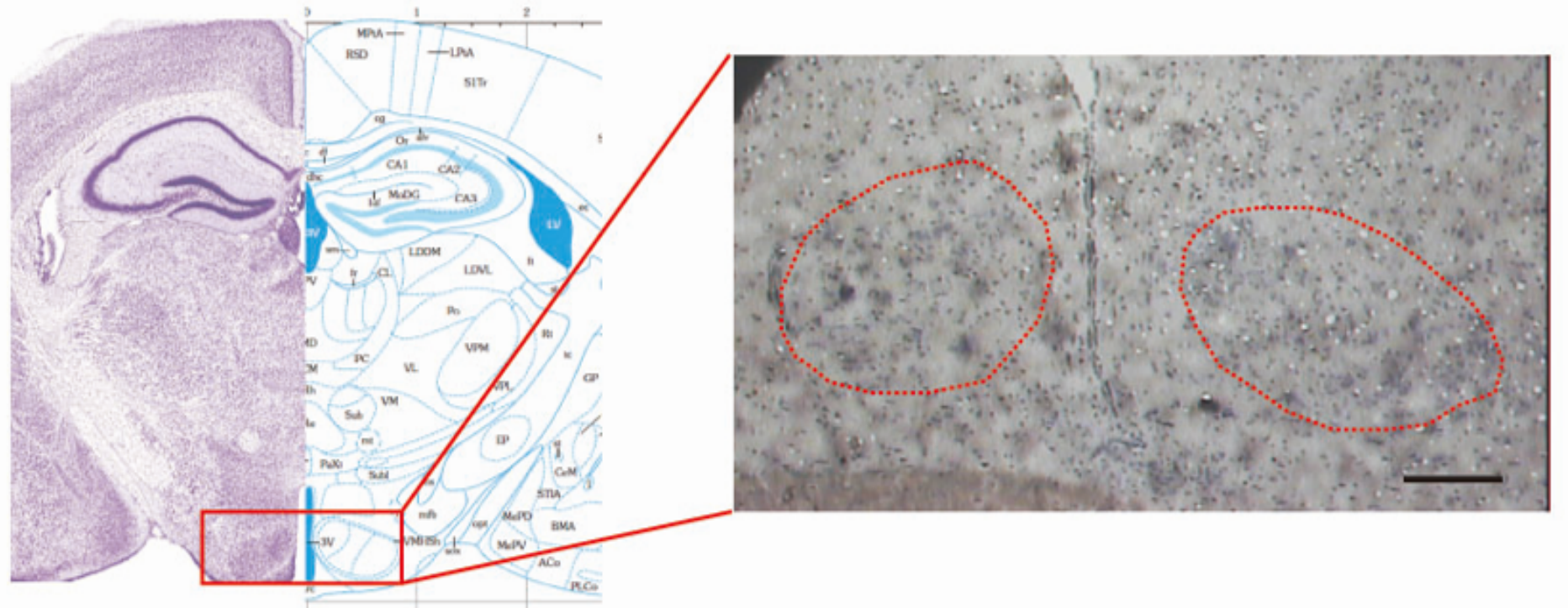

C

D

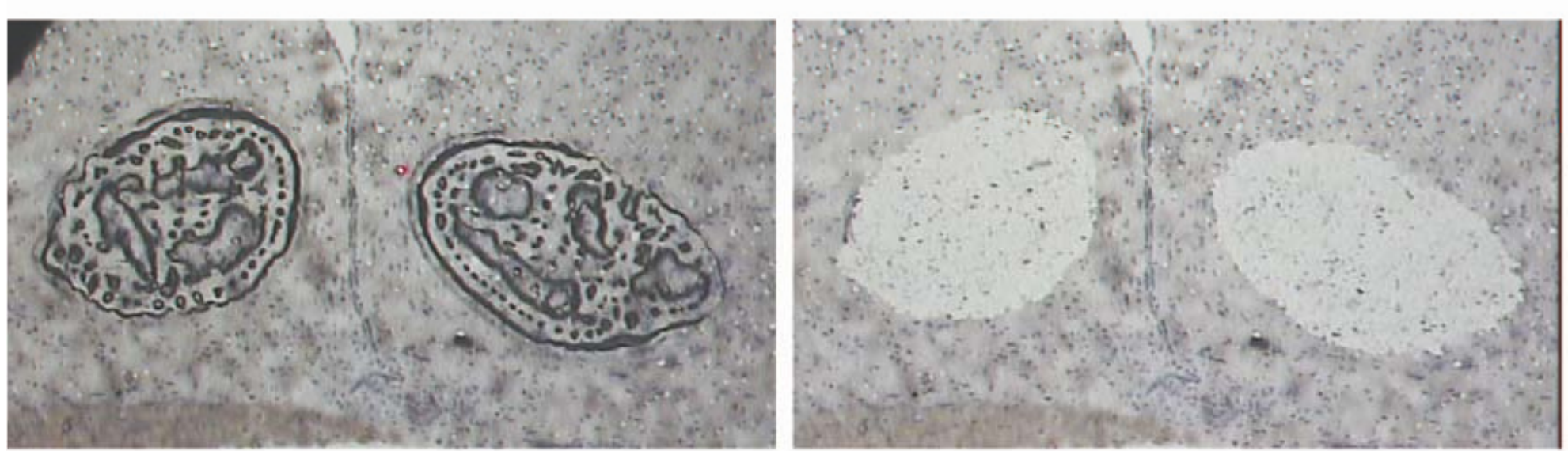

Fig 2 Segi-Nishida et al. 

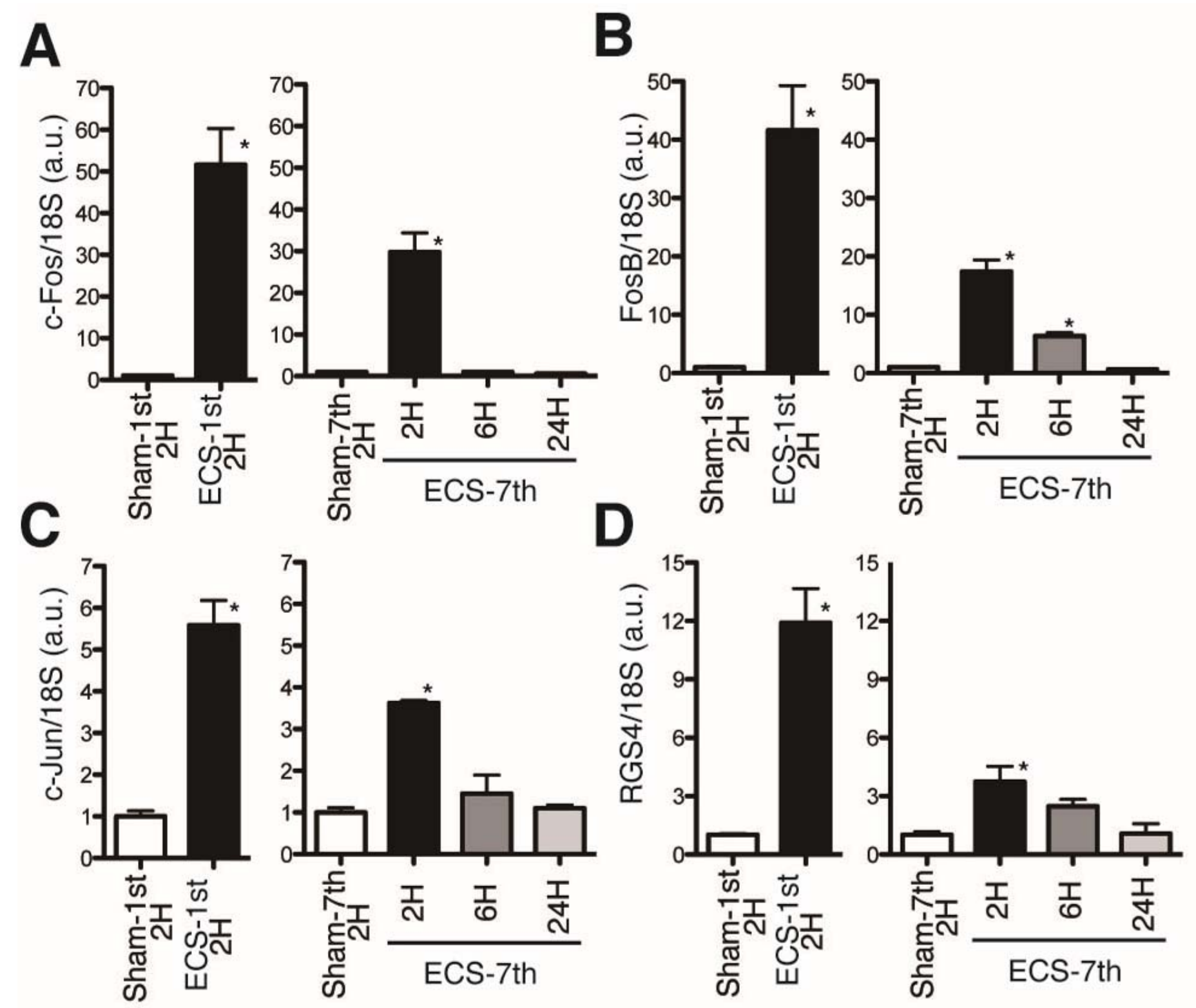

Fig 3

Segi-Nishida et al. 
A

B
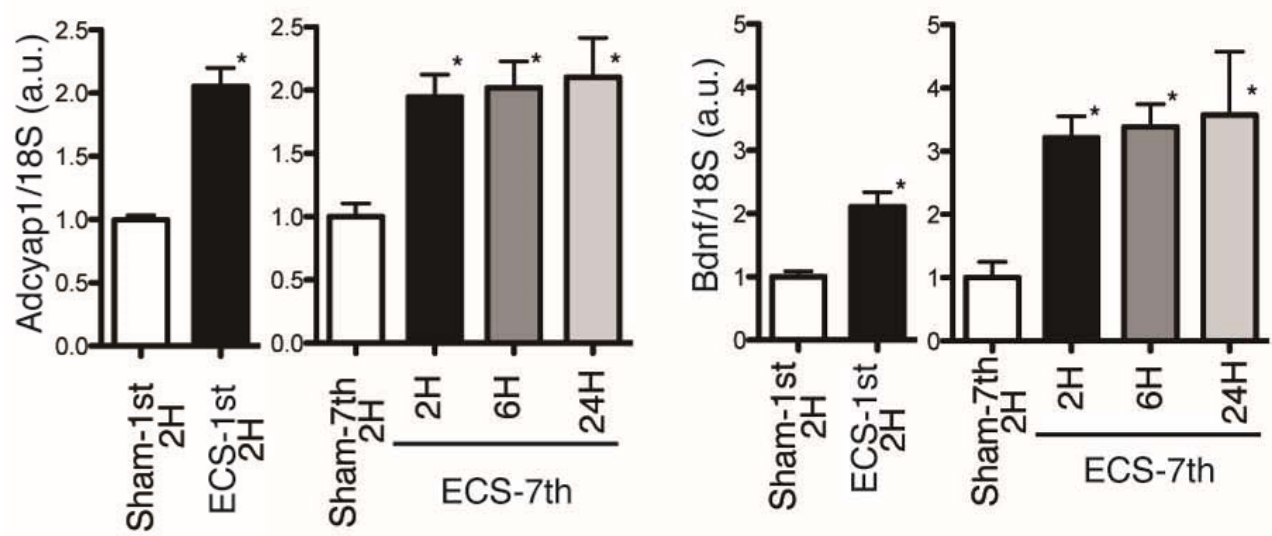

C

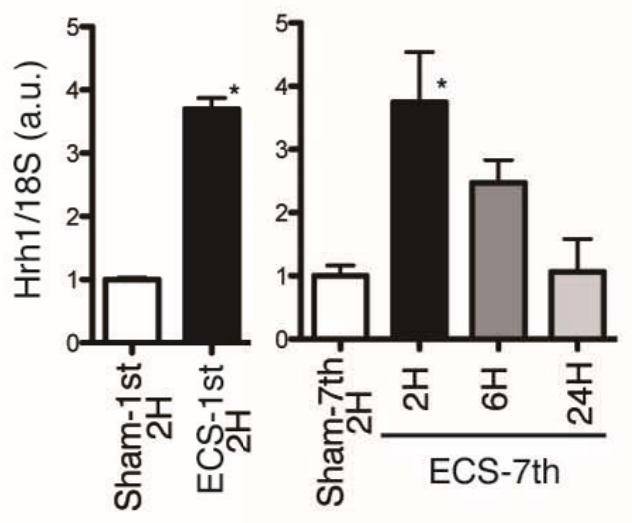

D

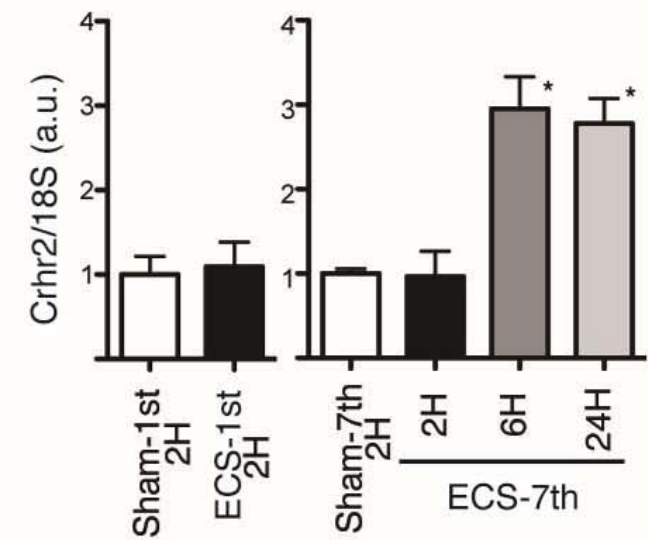

E

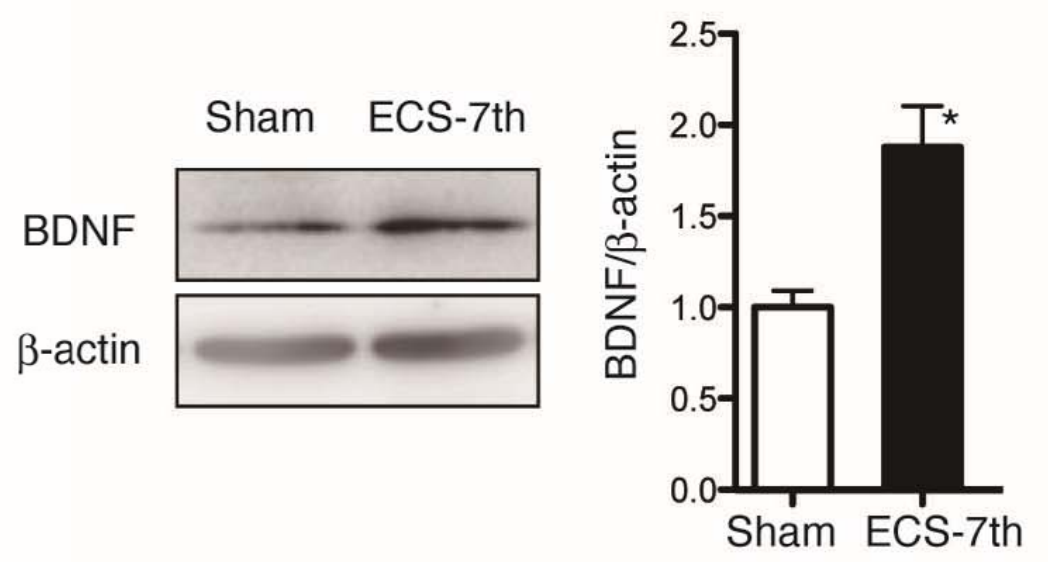

Fig 4

Segi-Nishida et al. 
A Sham-1st (2h) ECS-1st (2h) ECS-7th (2h)

Rgs4

B

FosB

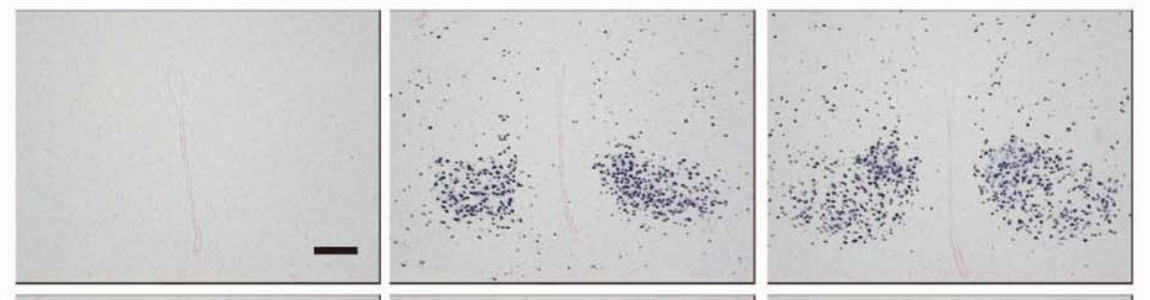

Adcyap1

(PACAP)

Bdnf

Hrh1
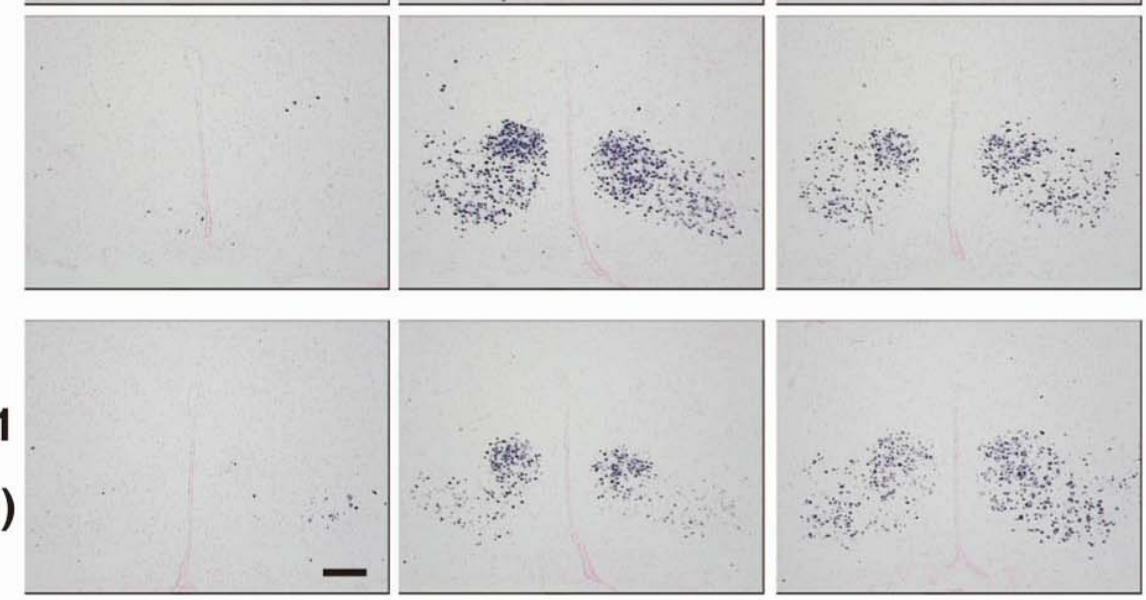

C

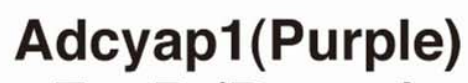

FosB (Red)

FosB (Brown)

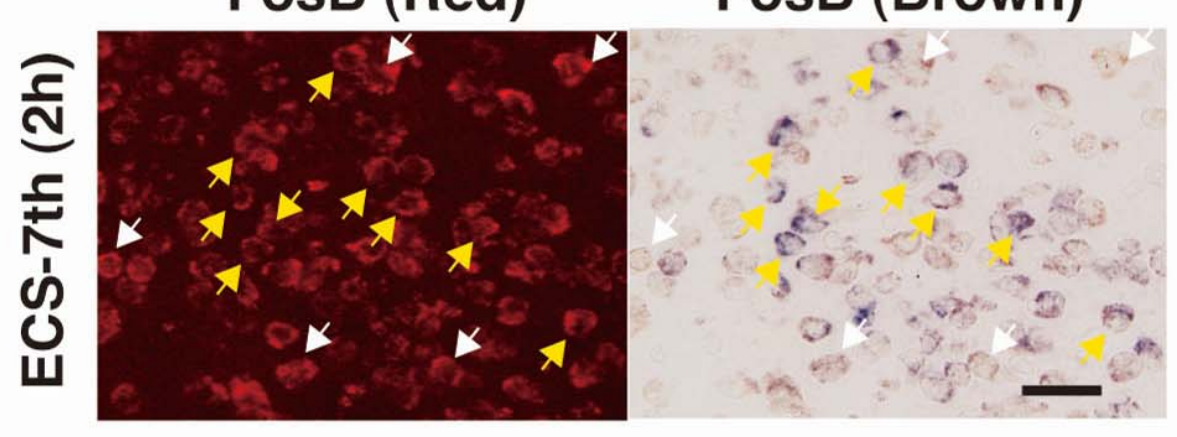

Fig 5

Segi-Nishida et al. 
A

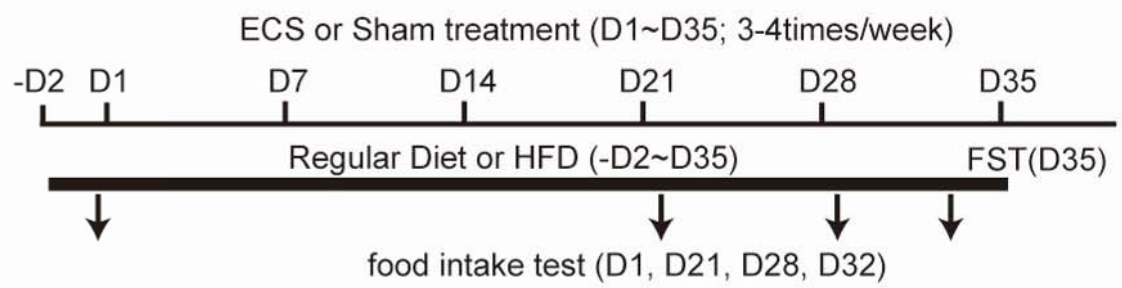

B

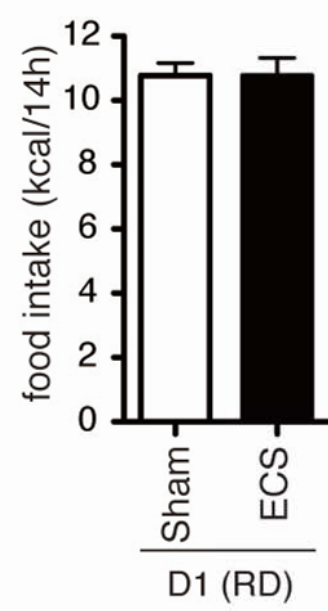

D

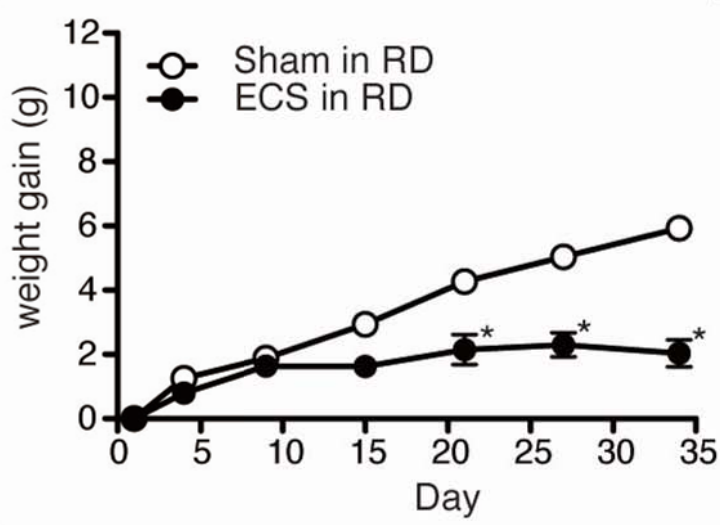

F

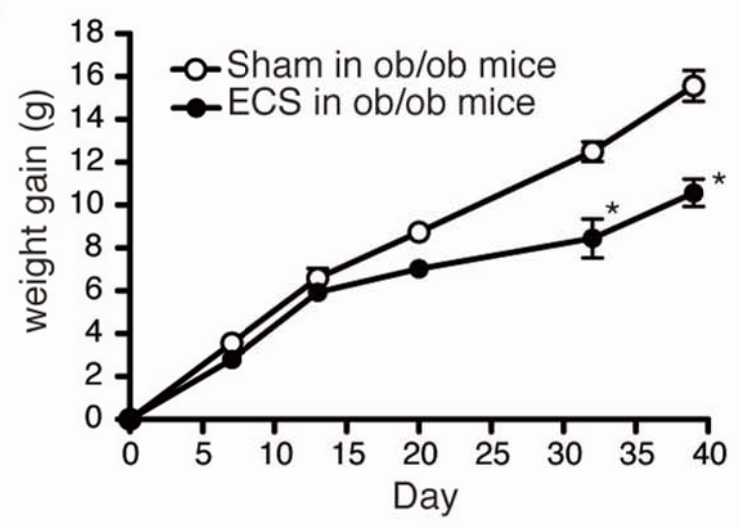

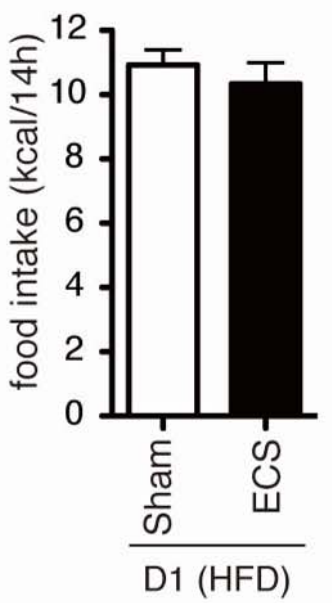

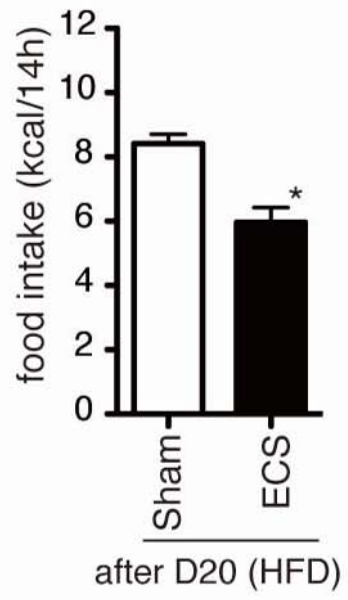

E

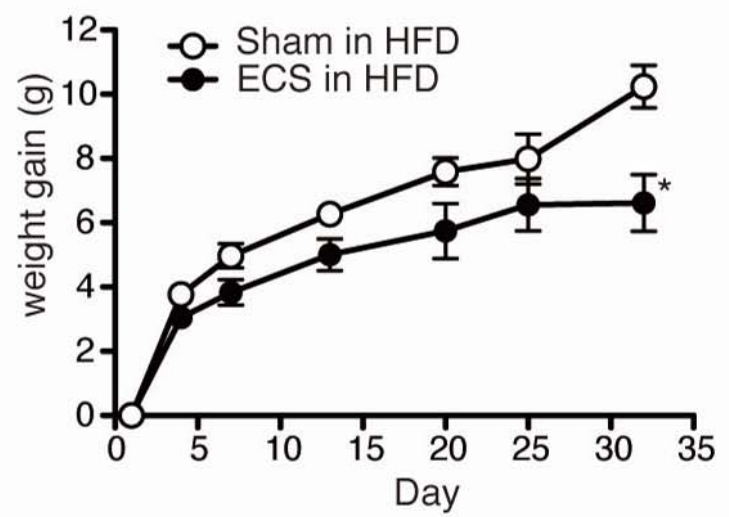

Fig 6

Segi-Nishida et al. 
A

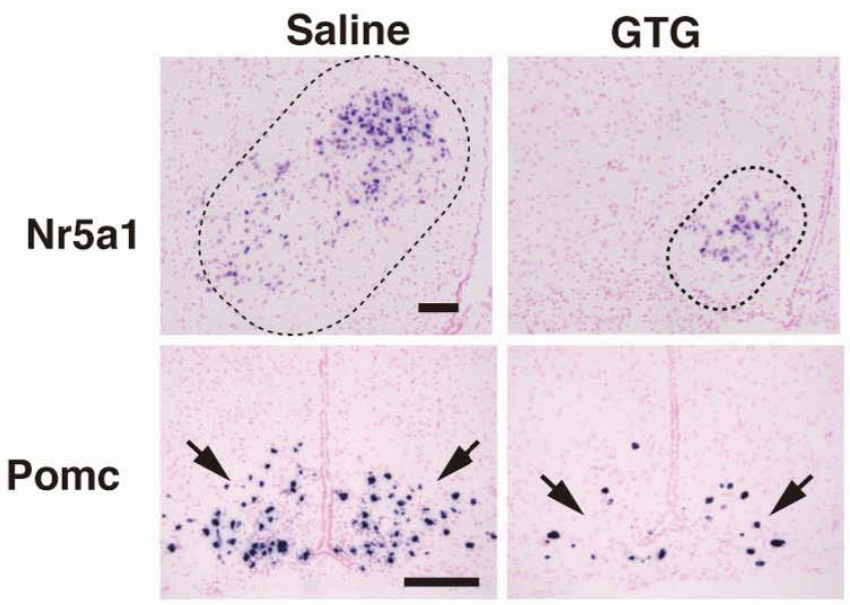

B

ECS-1st (2h)

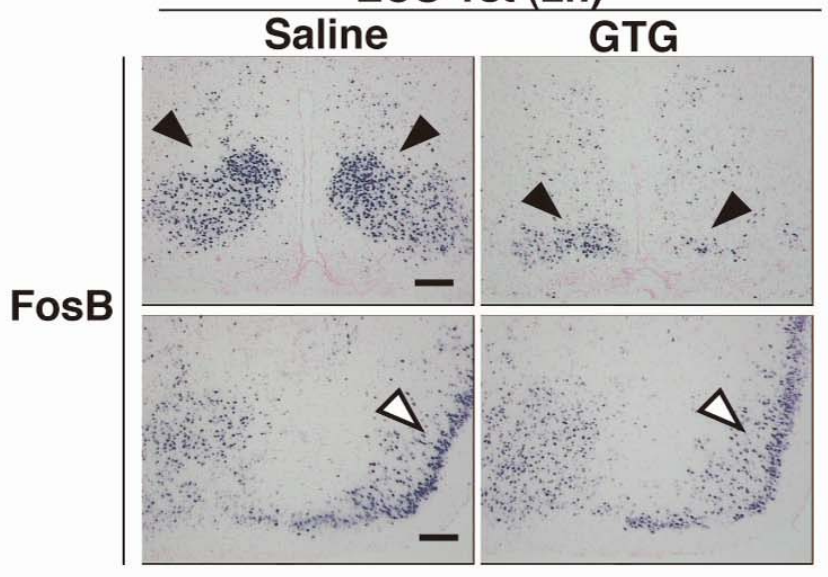

C

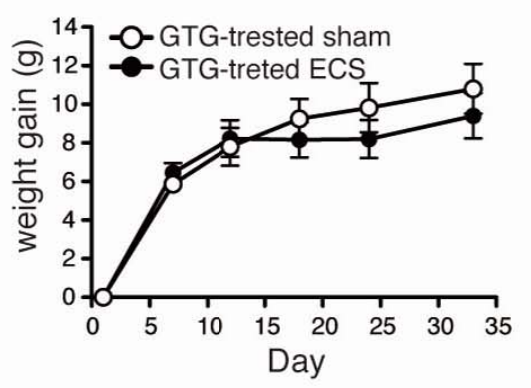

D

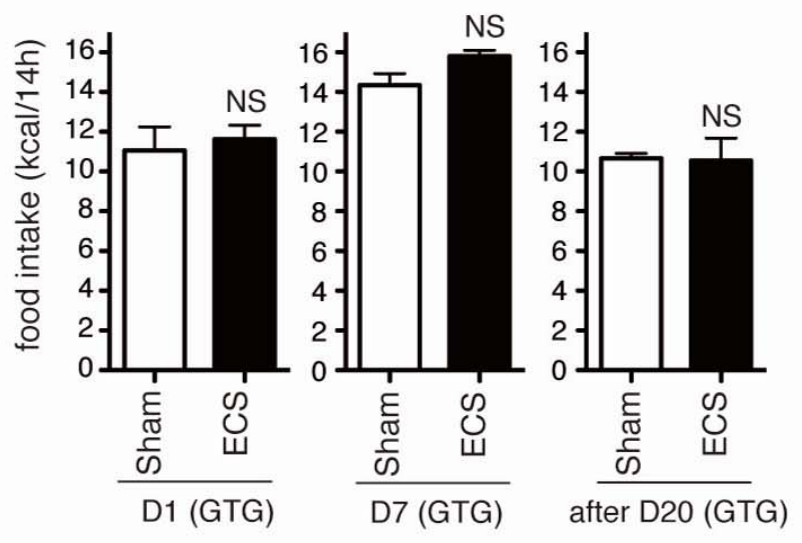

Fig 7

Segi-Nishida et al. 